\title{
sciendo
}

Int. J. of Applied Mechanics and Engineering, 2020, vol.25, No.2, pp.57-74

DOI: $10.2478 /$ ijame-2020-0020

\section{MHD MIXED CONVECTION IN COPPER-WATER NANOFLUID FILLED LID-DRIVEN SQUARE CAVITY CONTAINING MULTIPLE ADIABATIC OBSTACLES WITH DISCRETE HEATING}

\author{
R.S.R. GORLA* \\ Department of Mechanical Engineering \\ Cleveland State University \\ Cleveland, Ohio 44115 USA \\ E-mail: r.gorla@yahoo.com \\ S. SIDDIQA \\ COMSATS Institute of Information Technology \\ Kamra Road, 43600, Attock, PAKISTAN \\ A.A. HASAN and T. SALAH \\ Basic and Applied Sciences Department, College of Engineering and Technology \\ Arab Academy for Science \& Technology and Maritime Transport (AASTMT) \\ Aswan Branch, EGYPT \\ A.M. RASHAD \\ Department of Mathematics, Aswan University, Faculty of Science \\ Aswan, 81528, EGYPT
}

\begin{abstract}
The objective of the present work is to investigate the influence of nanoparticles of copper within the base fluid (water) on magneto-hydrodynamic mixed-convection flow in a square cavity with internal generation. A control finite volume method and SIMPLER algorithm are used in the numerical calculations. The geometry is a lid-driven square cavity with four interior square adiabatic obstacles. A uniform heat source is located in a part of the left wall and a part of the right wall of the enclosure is maintained at cooler temperature while the remaining parts of the two walls are thermally insulated. Both the upper and bottom walls of the cavity are considered to be adiabatic. A comparison with previously published works shows a very good agreement. It is observed that the Richardson number, Ri, significantly alters the behavior of streamlines when increased from 0.1 to 100.0. Also, the heat source position parameter, $D$, significantly changes the pattern of isotherms and its strength shifted when $D$ moves from 0.3 to 0.7 .
\end{abstract}

Keywords: nanofluid, mixed convection, magneto-hydrodynamics, square cavity, adiabatic obstacles.

\section{Introduction}

Nanofluid is a homogeneous mixture of dilute suspension of solid nanoparticles with an average size less than $100 \mathrm{~nm}$-diameter dispersed in a base fluid, such as water, ethylene glycol or oil. It is one of the effective passive strategies followed in heat transfer enhancement to increase the efficiency of numerous thermal systems, such as cooling of electronic components, heat exchangers, solar collectors, thermal storage, catalytic reactors, geothermal energy, design of packed bed reactor, biomedical devices, nuclear reactors, transformers, powder metallurgy, insulation of buildings and pipes, underground disposal of nuclear

\footnotetext{
* To whom correspondence should be addressed
} 
waste materials, and numerous others[1-3]. The study on nanofluids has become a very important topic among researchers. The existence of nanoparticles in the base fluids increases the effective thermal conductivity of the fluid and consequently promotesthe heat transfer rates as shown by Choi [4]. Boungiorno [5] studied a nonhomogeneous balance model by considering the influence of the Brownian diffusion and thermophoresis, that are very important mechanisms in a nanofluid. This model has been used by several investigators to study the heat transfer characteristics in nanofluids.

Heat transfer and fluid flow by mixed convection inside cavities has attracted the attention of several researchers because of its great applications in the environment and industry. Khanafar et al. [6] investigated different models of the thermophysical properties of $\mathrm{Cu}$-water. Convection in a lid-driven cavity is associated with many engineering applications. Several researchers investigated natural and mixed convection in a cavity under a wide range of thermal conditions in a square, rectangular and triangular cavity, both experimentally and numerically. Mansour et al. [7] studied mixed convection flows in a square lid-driven cavity partially heated from the bottom using a nanofluid. They concluded that an increase in solid volume fraction leads to a decrease in the fluid motion and temperature and increases the corresponding average Nusselt number. Talebi et al. [8] studied the mixed convection flow of an a no fluid in a square liddriven cavity. Ghasemi and Aminossadati [9], and Chamkha and Abu-Nada [10] studied the mixed convection in a lid-driven triangular cavity filled with nanofluid (water- $\mathrm{Al}_{2} \mathrm{O}_{3}$ ). They observed that for both upward and downward sliding walls and adding a larger solid volume fraction of nanoparticles into the pure water the rate of heat transfer increases. The effect of nanoparticles on mixed convection in a square cavity with hot obstacle in the center of the cavity was investigated by Mehrizi et al. [11]. Selimefendigil and Öztop [12] studied mixed convection in a lid driven trapezoidal cavity filled with Al2O3-water nanofluid under the effect of an inclined magnetic field for various electrical conductivity models. Rashad et al. [13] studied MHD mixed convection in a lid-driven square cavity filled with $\mathrm{Cu}$-water nanofluid.

Magnetic field affects convective heat transfer and has a large role in the precision electronic devices, purification of molten metals and many others. MHD mixed convection flows occur in many basic sciences such as fire research, metallurgy, astrophysics and nuclear engineering. Several studies have been conducted on the use of the external magnetic field to control heat transfer and fluid flow characteristics. Rashad et al. [14] studied the problem of magneto-hydrodynamic mixed convection in a square lid-driven cavity filled with nanofluid (Cu-water) in a saturated porous medium. Muneer et al. [15] studied the effect of inclined magnetic field on mixed convection in a lid-driven square cavity filled with $\mathrm{Cu}$-water nanofluid. The influence of the magnetic field on the natural convection and mixed convection flow in cavities with active or partially-active vertical and horizontal walls was investigated in references [16-17].

The objective of the current research is to investigate heat transfer characteristics of $\mathrm{Cu}$-water nanofluid inside a partially heated square cavity with multi inner adiabatic square obstacles. Fluid flow and heat transfer rate are displayed employing streamlines, isotherms and Nusselt number, respectively, for various pertinent parameters.

\section{Mathematical modeling}

The geometry of the present study is shown in Fig.1. It describes a lid-driven square cavity of length $H$ containing copper-water nanofluid with internal heat generation. Thermally insulated four square obstacles are placed in the cavity. Top and lower walls are adiabatic and moving with constant speed $U_{0}$, while other walls are kept at rest. A heat source with a constant volumetric rate $\left(q^{\prime \prime}\right)$ is placed on a part of the left wall and a part of the right wall of the enclosure is maintained at a cooled temperature $T_{c}$ with length $b$, while the other remaining parts of these two walls are thermally insulated. The nanofluid is Newtonian and incompressible and the flow is considered to be steady, two dimensional, laminar and generating heat at a uniform rate $Q_{0}$. The gravitational acceleration acts downward. A uniform magnetic field of strength $B_{0}$ is applied in the $x$-direction. The induced magnetic field generated by the movement of an electrically conducting fluid is assumed to be negligible as compared to the applied magnetic field. The base fluid (water) and solid nanoparticles $(\mathrm{Cu})$ are in thermal equilibrium. A standard Boussinesq model is used to approximate the density in the buoyancy term where the other thermo-physical properties of the nanofluid 
are assumed constant (see Tab.1). The governing equations of the flow and heat transfer for the current model may be written as

$$
\begin{aligned}
& \frac{\partial u}{\partial x}+\frac{\partial v}{\partial y}=0 \\
& u \frac{\partial u}{\partial x}+v \frac{\partial u}{\partial y}=-\frac{1}{\rho_{n f}} \frac{\partial p}{\partial x}+v_{n f}\left(\frac{\partial^{2} u}{\partial x^{2}}+\frac{\partial^{2} u}{\partial y^{2}}\right)+\frac{(\rho \beta)_{n f}}{\rho_{n f}} g\left(T-T_{c}\right), \\
& u \frac{\partial v}{\partial x}+v \frac{\partial v}{\partial y}=-\frac{1}{\rho_{n f}} \frac{\partial p}{\partial y}+v_{n f}\left(\frac{\partial^{2} v}{\partial x^{2}}+\frac{\partial^{2} v}{\partial y^{2}}\right)+\frac{(\rho \beta)_{n f}}{\rho_{n f}} g\left(T-T_{c}\right)-\frac{\sigma_{n f} B_{0}^{2}}{\rho_{n f}} v, \\
& u \frac{\partial T}{\partial x}+v \frac{\partial T}{\partial y}=\alpha_{n f}\left(\frac{\partial^{2} T}{\partial x^{2}}+\frac{\partial^{2} T}{\partial y^{2}}\right)+\frac{Q_{0}}{\left(\rho C_{p}\right)_{n f}}\left(T-T_{c}\right)
\end{aligned}
$$

where $u$ and $v$ are the velocity components along the $x$-and $y$-axes respectively, $T$ is the fluid temperature, $p$ is the fluid pressure, $g$ is the gravity acceleration, $\rho_{n f}$ is the density, $\mu_{n f}$ is the dynamic viscosity, $v_{n f}$ is the kinematic viscosity.

The boundary conditions are

$$
y=0,0 \leq x \leq H
$$

on the bottom wall $\quad u=\lambda_{b} U_{0}, \quad v=\frac{\partial T}{\partial y}=0$ :

$$
y=1, \quad 0 \leq x \leq H,
$$

on the top wall:

$$
u=\lambda_{t} U_{0}, \quad v=\frac{\partial T}{\partial y}=0
$$

$$
x=0, u=v=0,
$$

on the left wall: $\quad \frac{\partial T}{\partial x}=-\frac{q^{\prime \prime}}{k_{n f}}, \quad(d-0.5 b) \leq y \leq(d+0.5 b)$

$$
\frac{\partial T}{\partial x}=0 \quad \text { otherwise }
$$

$x=1, \quad u=v=0$,

on the right wall: $\quad T=T_{c},(d-0.5 b) \leq y \leq(d+0.5 b)$

$$
\frac{\partial T}{\partial x}=0 \quad \text { otherwise }
$$

Numerous formulations for the thermo-physical properties of nanofluids are proposed in the literature. In the present study, we are adopting the relations which depend on the nanoparticles volume 
fraction only and which were proven and used in many previous studies (Aminossadati and Ghasemi [19] and Khanfer et al. [20]).

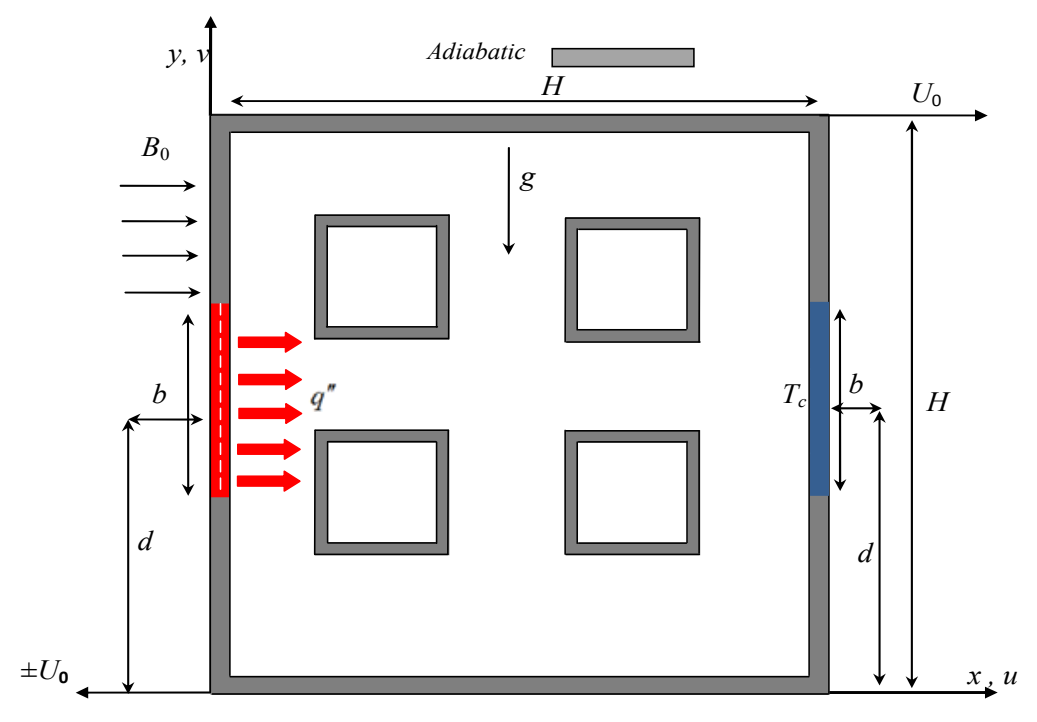

Fig.1. Schematic diagram and coordinate system.

Table 1. Thermo-physical properties of water and nanoparticles [13, 15].

\begin{tabular}{|c|c|c|}
\hline Property & Pure water & Copper $(\mathrm{Cu})$ \\
\hline$\rho\left(\mathrm{kg} \mathrm{m}^{-3}\right)$ & 997.1 & 8933 \\
\hline$C_{p}\left(\mathrm{Jkg}^{-1} \mathrm{~K}^{-1}\right)$ & 4179 & 385 \\
\hline$k\left(\mathrm{Wm}^{-1} \mathrm{~K}^{-1}\right)$ & 0.613 & 401 \\
\hline$\beta\left(\mathrm{K}^{-1}\right)$ & $21 \times 10^{-5}$ & $1.67 \times 10^{-5}$ \\
\hline$\sigma(\mu \mathrm{S} / \mathrm{cm})$ & 0.05 & $5.96 \times 10^{7}$ \\
\hline
\end{tabular}

The effective density of the nanofluid is given as

$$
\rho_{n f}=(1-\phi) \rho_{f}+\phi \rho_{p}
$$

where $\phi$ is the solid volume fraction of the nanofluid, $\rho_{f}$ and $\rho_{p}$ are the densities of the fluid and of the solid fractions, respectively, and the heat capacitance of the nanofluid is given by Khanafer et al. [20] as

$$
\left(\rho c_{p}\right)_{n f}=(1-\phi)\left(\rho c_{p}\right)_{f}+\phi\left(\rho c_{p}\right)_{p} .
$$

The thermal expansion coefficient of the nanofluid can be determined by

$$
(\rho \beta)_{n f}=(1-\phi)(\rho \beta)_{f}+\phi(\rho \beta)_{p}
$$

where $\beta_{f}$ and $\beta_{p}$ are the coefficients of thermal expansion of the fluid and of the solid fractions, respectively. 
Thermal diffusivity, $\alpha_{n f}$ of the nanofluid is defined by Abu-Nada and Chamkha [21] as

$$
\alpha_{n f}=\frac{k_{n f}}{\left(\rho c_{p}\right)_{n f}} .
$$

In Eq.(2.9), $k_{n f}$ is the thermal conductivity of the nanofluid which for spherical nanoparticles, according to the Maxwell-Garnetts model, [22] is

$$
\frac{k_{n f}}{k_{f}}=\frac{\left(k_{p}+2 k_{f}\right)-2 \phi\left(k_{f}-k_{p}\right)}{\left(k_{p}+2 k_{f}\right)+\phi\left(k_{f}-k_{p}\right)} .
$$

The effective dynamic viscosity of the nanofluid based on the Brinkman model [23] is given by

$$
\mu_{n f}=\frac{\mu_{f}}{(1-\phi)^{2.5}}
$$

where $\mu_{f}$ is the viscosity of the fluid fraction and the effective electrical conductivity of the nanofluid was presented by Maxwell [22] as

$$
\frac{\sigma_{n f}}{\sigma_{f}}=1+\frac{3(\gamma-1) \phi}{(\gamma+2)-(\gamma-1) \phi}
$$

where

$$
\gamma=\frac{\sigma_{p}}{\sigma_{f}}
$$

Introducing the following dimensionless set

$$
\begin{aligned}
& X=\frac{x}{H}, \quad Y=\frac{y}{H}, \quad U=\frac{u}{U_{0}}, \quad V=\frac{v}{U_{0}}, \quad P=\frac{p}{\rho_{n f} U_{0}^{2}}, \quad \theta=\frac{\left(T-T_{c}\right)}{q^{\prime \prime} H} k_{f}, \\
& B=\frac{b}{H}, \quad D=\frac{d}{H}, \quad R i=\frac{\mathrm{Gr}}{\operatorname{Re}^{2}}, \quad Q=\frac{Q_{0} H^{2}}{\left(\rho c_{p}\right)_{f} \alpha_{f}}, \\
& \mathrm{Gr}=\frac{g \beta_{f} q^{\prime \prime} H^{4}}{v_{f}^{2} k_{f}}, \quad \operatorname{Pr}=\frac{v_{f}}{\alpha_{f}}, \quad \operatorname{Re}=\frac{U_{0} H}{v_{f}}, \quad H a=B_{0} H \sqrt{\sigma_{f} / \mu_{f}},
\end{aligned}
$$

into Eqs (2.1)-(2.5) yields the following dimensionless equations

$$
\begin{aligned}
& \frac{\partial U}{\partial X}+\frac{\partial V}{\partial Y}=0 \\
& U \frac{\partial U}{\partial X}+V \frac{\partial U}{\partial Y}=-\frac{\partial P}{\partial X}+\frac{1}{\operatorname{Re}}\left(\frac{v_{n f}}{v_{f}}\right)\left(\frac{\partial^{2} U}{\partial X^{2}}+\frac{\partial^{2} U}{\partial Y^{2}}\right)+R i \frac{(\rho \beta)_{n f}}{\rho_{n f} \beta_{f}} \theta,
\end{aligned}
$$




$$
\begin{aligned}
& U \frac{\partial V}{\partial X}+V \frac{\partial V}{\partial Y}=-\frac{\partial P}{\partial Y}+\frac{1}{\operatorname{Re}}\left(\frac{v_{n f}}{v_{f}}\right)\left(\frac{\partial^{2} V}{\partial X^{2}}+\frac{\partial^{2} V}{\partial Y^{2}}\right)+R i \frac{(\rho \beta)_{n f}}{\rho_{n f} \beta_{f}} \theta-\left(\frac{\rho_{f}}{\rho_{n f}}\right)\left(\frac{\sigma_{n f}}{\sigma_{f}}\right) \frac{H a^{2}}{\operatorname{Re}} V, \\
& U \frac{\partial \theta}{\partial X}+V \frac{\partial \theta}{\partial Y}=\left(\frac{1}{\operatorname{Pr} \cdot \operatorname{Re}}\right)\left(\frac{\alpha_{n f}}{\alpha_{f}}\right)\left(\frac{\partial^{2} \theta}{\partial X^{2}}+\frac{\partial^{2} \theta}{\partial Y^{2}}\right)+\frac{1}{\operatorname{Re} \operatorname{Pr}} \frac{\left(\rho c_{p}\right)_{f}}{\left(\rho c_{p}\right)_{n f}} Q \theta .
\end{aligned}
$$

The dimensionless boundary condition for Eqs (2.14)-(2.17) are as follows

$$
\begin{aligned}
& Y=0, \quad 0 \leq X \leq 1, \\
& \text { on the bottom wall: } \quad U=\lambda_{b}, \quad V=\frac{\partial \theta}{\partial Y}=0, \\
& Y=1, \quad 0 \leq X \leq 1,
\end{aligned}
$$

on the top wall:

$$
\begin{aligned}
& U=\lambda_{t}, \quad V=\frac{\partial \theta}{\partial Y}=0, \\
& X=0, \quad U=V=0,
\end{aligned}
$$

on the left wall:

$$
\frac{\partial \theta}{\partial X}=-\frac{k_{f}}{k_{n f}}, \quad(D-0.5 B) \leq Y \leq(D+0.5 B)
$$

$$
\frac{\partial \theta}{\partial X}=0 \quad \text { otherwise }
$$

$$
X=1, U=V=0,
$$

on the right wall: $\quad \theta=0,(D-0.5 B) \leq Y \leq(D+0.5 B)$

$$
\frac{\partial \theta}{\partial X}=0 \quad \text { otherwise }
$$

where $\lambda_{t}$ and $\lambda_{b}$ are the moving parameters on the top and bottom walls, respectively.

The local Nusselt number is defined as

$$
\mathrm{Nu}_{s}=\frac{1}{(\theta)_{\text {heat source }}}
$$

and the average Nusselt number is defined as

$$
\mathrm{Nu}_{m}=\frac{1}{B} \int_{D-0.5 B}^{D+0.5 B} \mathrm{Nu}_{s} d Y
$$

\section{Numerical solution and validation}

In the present investigation, the finite volume procedure is applied to solve the governing equations, which integrates these equations over finite control volumes, performing a collection of algebraic equations that can be solved numerically. Staggered grids are utilized where the velocities are computed at the position 
of the volume interfaces whilst the pressure and the other scalar quantity such as temperature is calculated at the center of the control volumes. The algebraic discretization equations have been solved iteratively throughout the physical domain by utilizing the known TDMA mechanism, using the SIMPLE algorithm[24].The pressure and velocity are linked utilizing the Semi Implicit Method for Pressure Linked Equations (SIMPLE). Convergence of the iterative solution is guaranteed while the change of all variables is lower than $10^{-6}$. The non-uniform grid contains of $101 \times 101$ grid nodes in the $x$ - and $y$ - directions, respectively. The obtained data are separated by the number of the grids.

Figure 2 displays a comparison between the temperature contour reported in this investigation with those of Khanafar and Chamkha [25] and Iwatsu et al. [26]. The data show an excellent agreement between this investigation and the previously published investigations.
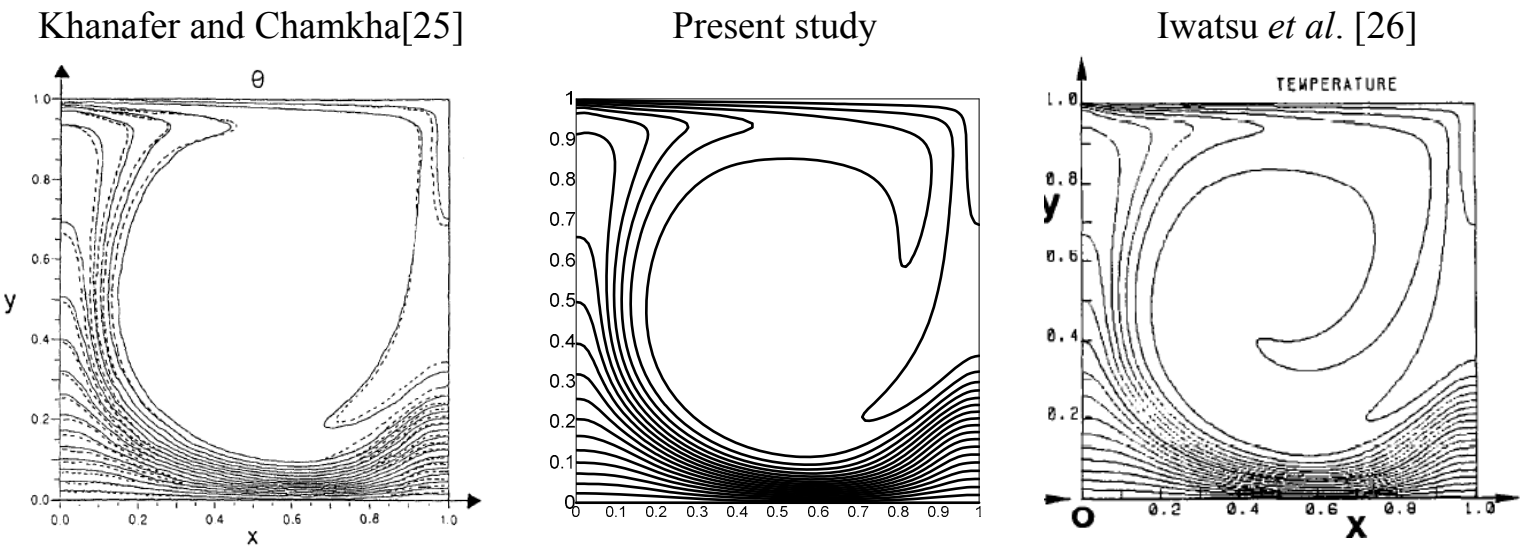

Fig.2. Comparison of the present study with $\mathrm{Re}=1000.0, \mathrm{Gr}=10^{2}, \phi=0.0, \operatorname{Pr}=0.71$.

\section{Results and discussion}

In this paper, a finite volume based algorithm is applied to obtain the numerical solutions of a mixed convection MHD flow in a copper-water nanofluid filled in a lid-driven square cavity/rigid wall cavity loaded with multiple adiabatic obstacles having discrete heating. The total obstacles are four in number, having the same size and shape (square shaped), and placed at equidistant from each other. The boundary walls of the cavity are subject to the conditions prescribed in Eq.(2.19). Results are interpreted in the form of local and average Nusselt numbers, streamlines and isotherms. The parametric study revolves around the following dimensionless parameters: Reynolds number, Re, Richardson number, Ri, Hartman number, Ha, Prandtl number, $\operatorname{Pr}$, heat generation or absorption coefficient, $Q$, nanoparticles volume fraction, $\phi$, heat source length, $B$, heat source position, $D$, moving parameter on the top wall, $\lambda_{t}$, and moving parameter on the bottom wall, $\lambda_{b}$. The main attention has been paid to the effects of the above governing parameters on the fluid flow and heat transfer. Throughout the simulation process the Reynolds number, Re, and Prandtl number, Pr, are fixed to 10 and 6.2, respectively for obtaining the solutions of the problem.

In Fig.3 streamlines and isotherms are presented for different values of the heat source length parameter, $B$, while other parameters are $\mathrm{Ha}=10.0, D=0.5, Q=1.0, \mathrm{Ri}=10.0, \phi=0.05, \lambda_{t}=-\lambda_{b}=1.0$. Initially, the streamline contours start developing in the cavity with obstacles and settle down in the region between the obstacles and cavity walls when $B$ increases from 0.2 to 0.8 . It is observed that the density of the temperature contours, particularly in the middle section of the rigid cavity decreases, and ultimately heat exchange decreases in this region for higher values of $B$. As soon as temperature difference increases, the buoyancy force decreases and the influence of shear-driven force increases. It can also be seen in Fig.3a that large clockwise vortices are produced in the top, bottom and middle of the cavity and become stronger due to heating from the heat source. The variation of $B$ in terms of the local Nusselt number and average Nusselt number is presented in Figs 4-5. The local Nusselt number is given along the heat source whereas the 
average Nusselt number is shown against $\phi$ and Ha. The magnitude of the local and average Nusselt number decreases considerably for nanofluid suspension when $B$ increases. This happens because the thermal conductivity of the nanofluid decreases and therefore $\mathrm{Nu}_{s}$ and $\mathrm{Nu}_{m}$ diminish considerably.

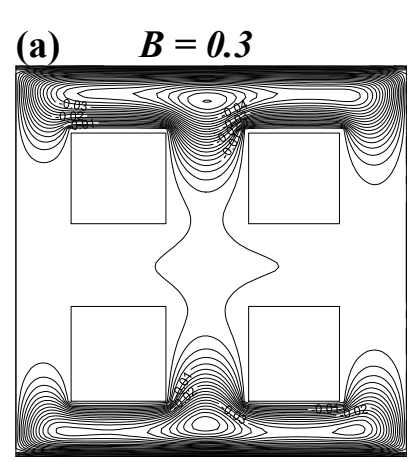

$B=0.4$

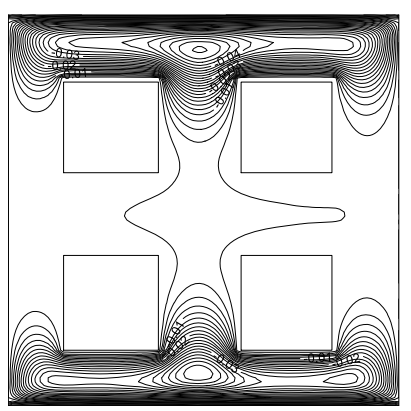

$B=0.6$

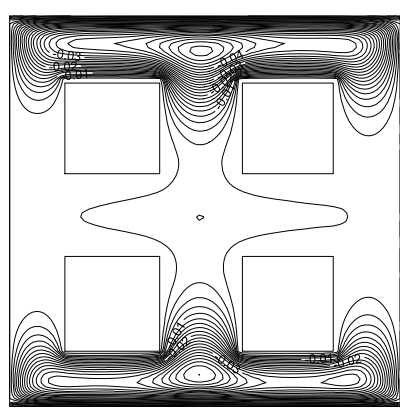

$B=0.7$

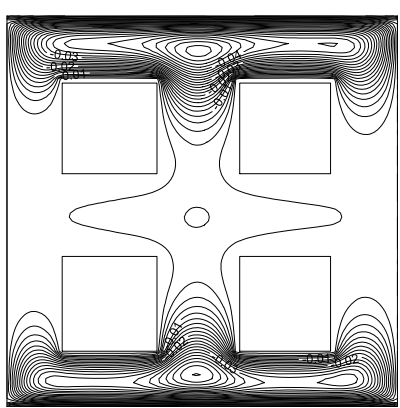

(b)
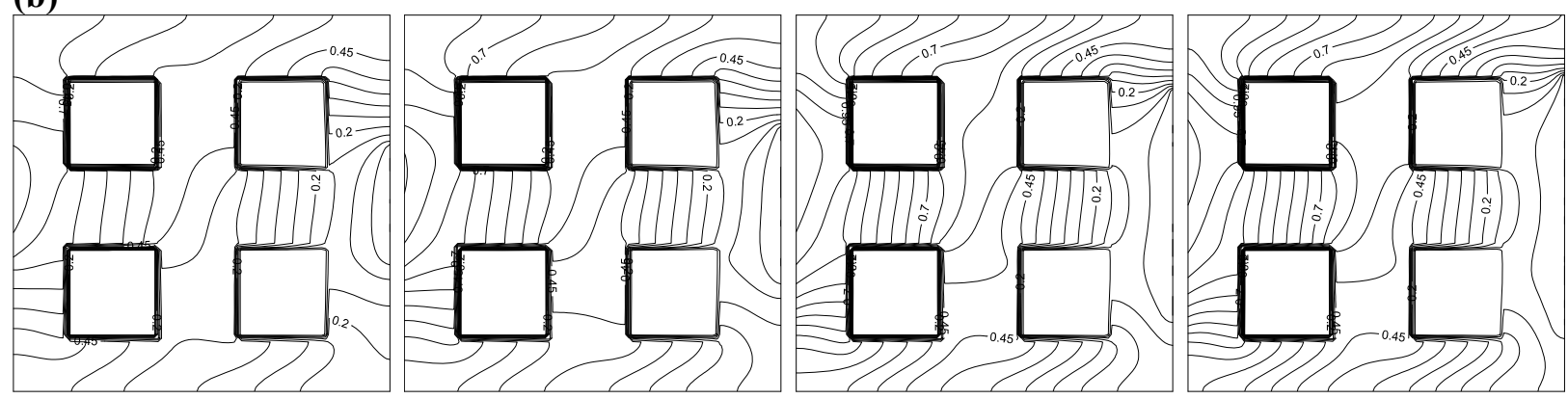

Fig.3a. Streamlines and (b) Isotherms for $\mathrm{Ha}=10.0, D=0.5, Q=1.0, \mathrm{Ri}=10.0, \phi=0.05, \lambda_{t}=-\lambda_{b}=1.0$

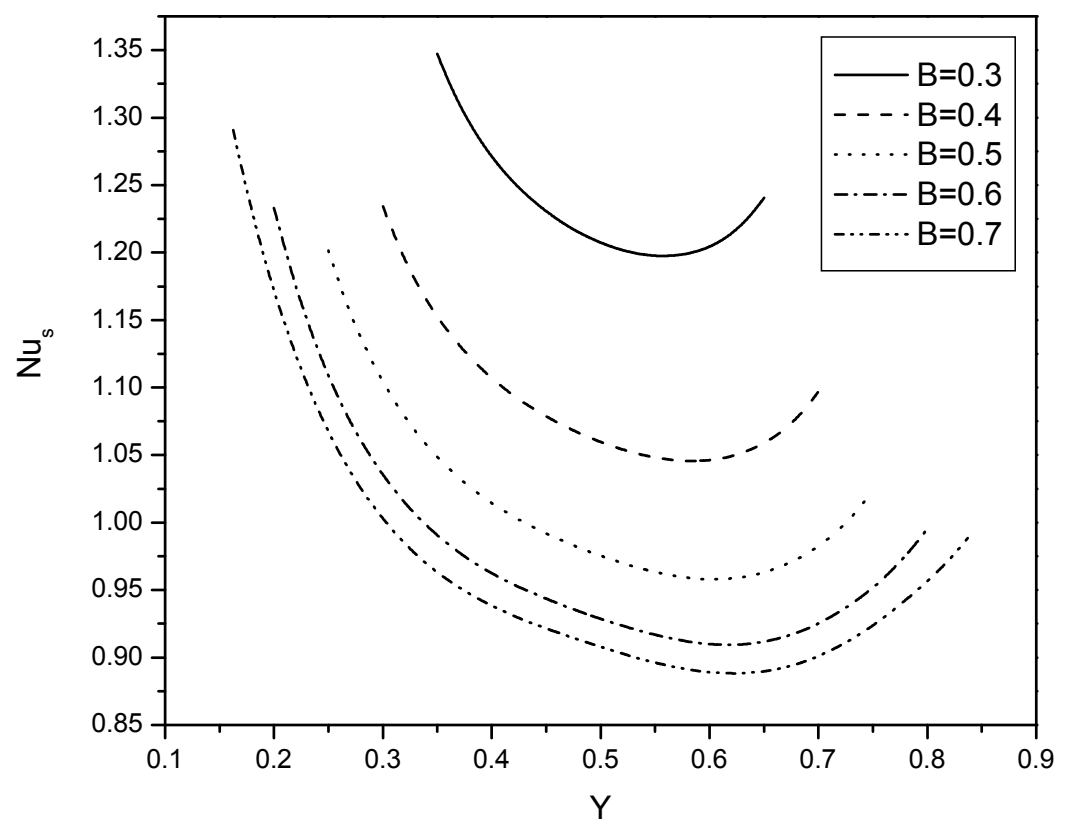

Fig.4. Variation of local Nusselt number along the heat source for $\mathrm{Ha}=10.0, D=0.5$, $Q=1.0, \mathrm{Ri}=10.0, \phi=0.05, \lambda_{t}=-\lambda_{b}=1.0$ 


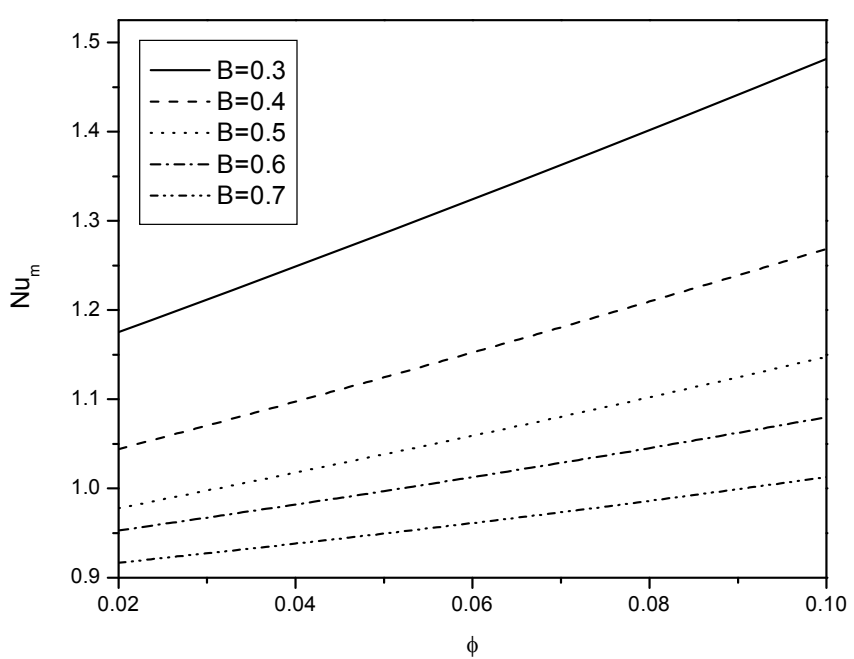

Fig.5a. Variation of the average Nusselt number for $\mathrm{Ha}=10, D=0.5, Q=1.0, R i=10.0$, $\lambda_{t}=-\lambda_{b}=1.0$.

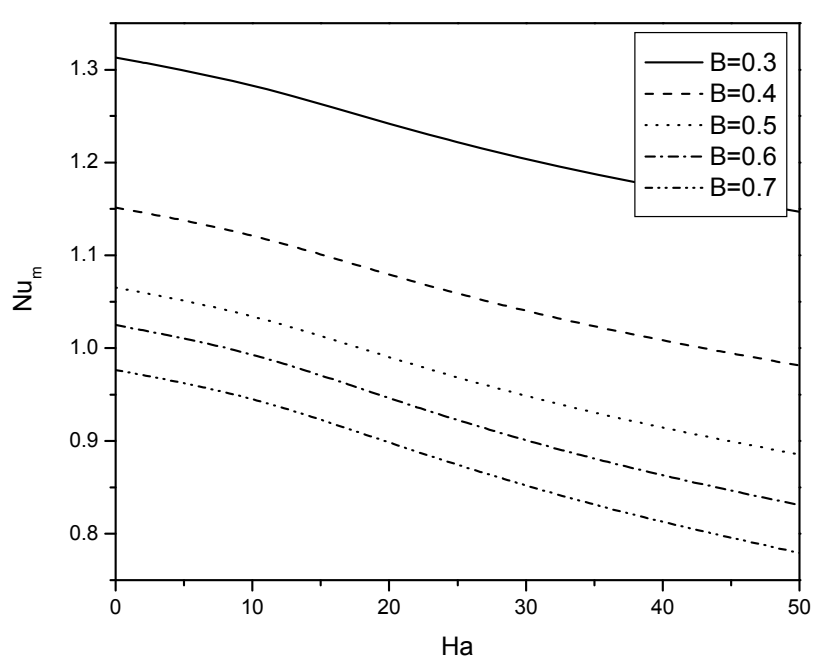

Fig.5b. Variation of the average Nusselt number for $\phi=0.05, D=0.5, Q=1.0, \mathrm{Ri}=10.0$, $\lambda_{t}=-\lambda_{b}=1.0$.

The influence of various locations of the heat source, $D$, on streamlines and isotherms is given in Fig.6. It is found that the intensification of the fluid flow and temperature distribution decreases when $D$ increases. That is, the strength of the fluid flow and heat transfer is shifted from the lower part of the cavity to the upper part when the heat source moves. In Fig.6a, the contours between the blocks connect each other for a smaller value of $D$ and recirculation cells cover the whole cavity except the left wall. The eddy formed in the middle of the cavity becomes weaker due to an increase in $D$ and minimum contours occur at the center of the cavity. We may conclude that tricellular contours gradually transformed to the bicellular flow because the central eddy loses its strength owing to an increase in $D$. The isotherm lines also concentrate much near the square obstacles and reduce their strength as soon as $D$ enhances. The influence of the different locations of the heat source $D$ is also observed on local and average Nusselt number in Figs 7 and 8 , respectively. Both the quantities increase significantly when the heat source is relocated from the position $D$ $=0.3$ to the position $D=0.7$. The contours of the temperature lines are shifted due to convection. Particularly graphs of the local Nusselt number are concaved-upward for all the values of $D$. That is, local Nusselt number is maximum at the walls of the cavity and minimum at the center. This is due to conduction dominance at the center and convection is dominating at the edges of the cavity walls. Enhancement in the magnitude of the average Nusselt number shows that the heat transfer rate is higher when the heat source is moved from the lower to the upper part of the cavity wall. The preferable location of the heat source is therefore subject to the practical application.

The effect of the heat generation parameter, $Q$, on streamlines and isotherms for $D=0.5, B=0.5$, $\mathrm{Ri}=10.0, \phi=0.05, \mathrm{Ha}=10.0, \lambda_{t}=-\lambda_{b}=1.0$ is illustrated in Fig.9. Heat generation applied may either act as a heat source or heat sink. This can be observed through the sign convention, i.e., when $Q>0.0$ the heat generation parameter will act as a heat source, when $Q<0.0$ the heat generation parameter will represent a heat sink and lastly, when $Q=0.0$ there is no heat generation in the cavity. The streamline contours at the top and bottom of the cavity seem stable for all values of $Q$ except in the middle. It is observed that the velocity contours are absent at the left and right walls of the cavity for $Q<0.0$ and three recirculation cells are formed at the top, bottom and middle of the cavity. Out of these three contours the strength of the middle one is weak (minor vortex) as compared to other recirculation cells. The behaviour of the heat generation parameter, $Q$, changes as soon as its value becomes positive from negative. That is, the strength of the contours in the middle and also near the right most wall of the cavity becomes strong. The effect of the heat generation parameter on isotherms is more pronounced and fluid temperature increases when $Q<0.0$ whereas an opposite behaviour is noted when $Q>0.0$. In fact, $Q<0.0$ produces a hot layer of the fluid near the left wall 
of the cavity loaded with obstacles which results in an increase of temperature in the fluid. For $Q<0.0$, a localized region of high temperature is noticed close to the left hot wall and its effect extends towards the adiabatic walls of the cavity. For $Q \geq 0.0$, less energy is noticed to be carried away from i) the moving top wall into the cavity (for $Q=0.0$ ) ii) the left wall into the cavity (for $Q>0.0$ ), and subsequently, the conduction heat transfer regime has become the dominant mode of energy transport in the cavity. Figures 1011 depict the time history of the local and average Nusselt number and show that both physical quantities decrease significantly owing to an increase in the heat generation parameter from -2.0 to 2.0. This means that convection is not dominant in the obstacles loaded cavity and results in a reduction in the heat transfer rate.

(a) $D=0.3$

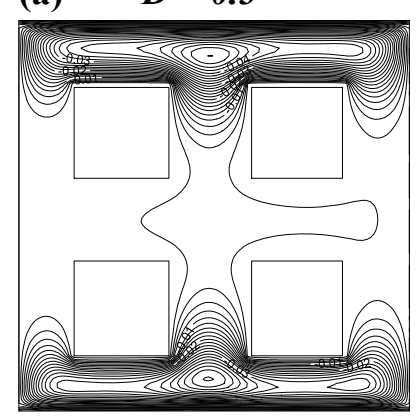

(b)

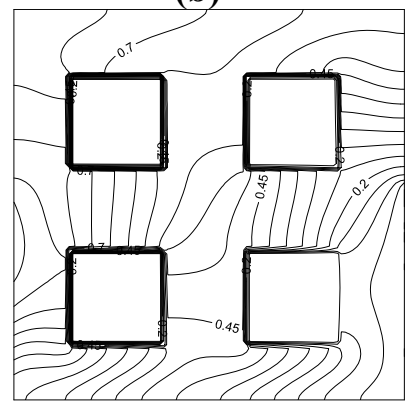

$$
D=0.4
$$
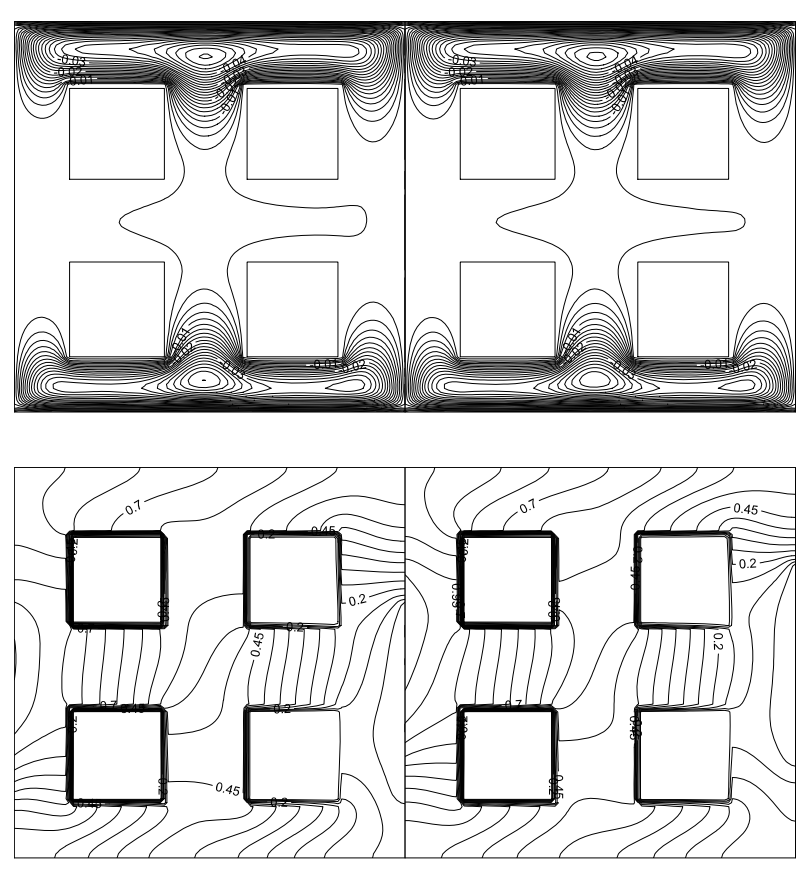

$D=0.5$

(b) Isotherms

Fig.6a. Streamlines and

$D=0.6$
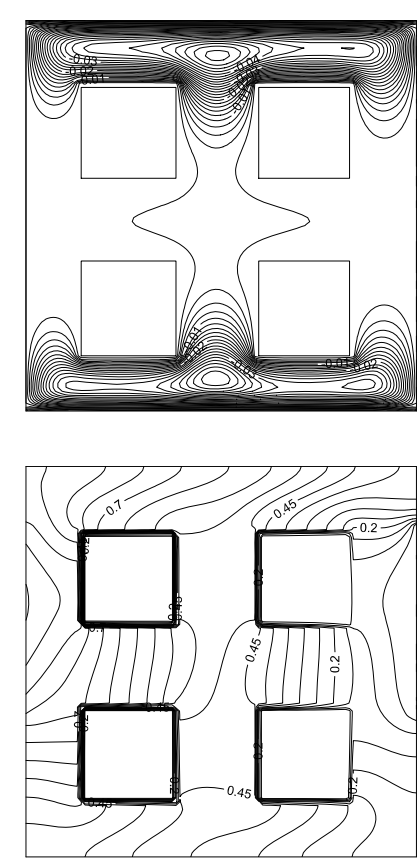
$\lambda_{t}=-\lambda_{b}=1.0$.

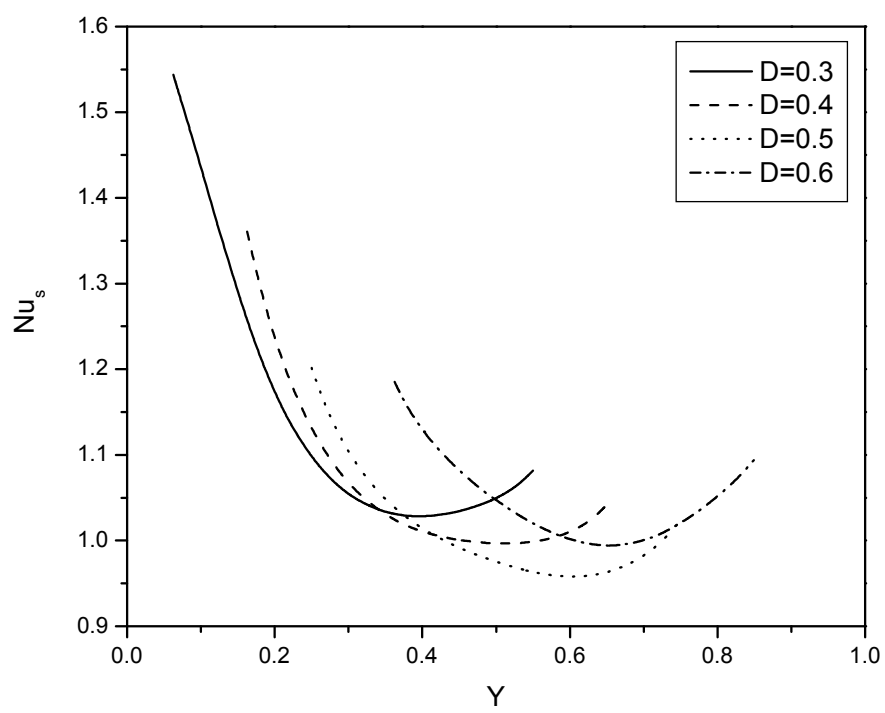

Fig.7. Variation of local Nusselt number along the heat source for $\mathrm{Ha}=10.0, B=0.5, Q=1.0$, $\mathrm{Ri}=10.0, \phi=0.05, \lambda_{t}=-\lambda_{b}=1.0$. 


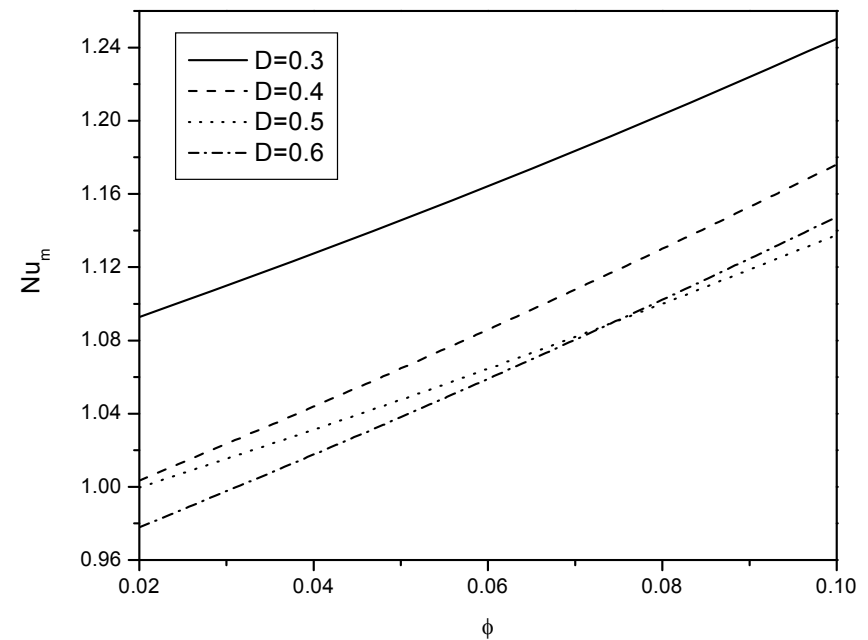

Fig.8a. Variation of the average Nusselt number for $\mathrm{Ha}=10.0, B=0.5, Q=1.0, \mathrm{Ri}=10.0$, $\lambda_{t}=-\lambda_{b}=1.0$.
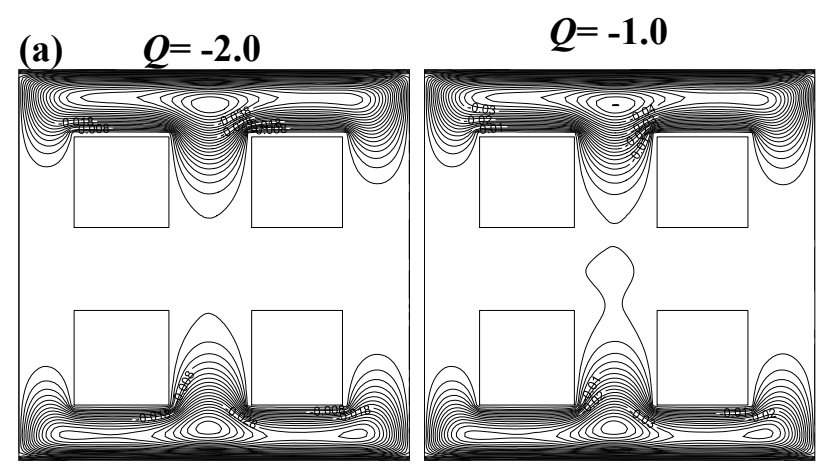

(b)
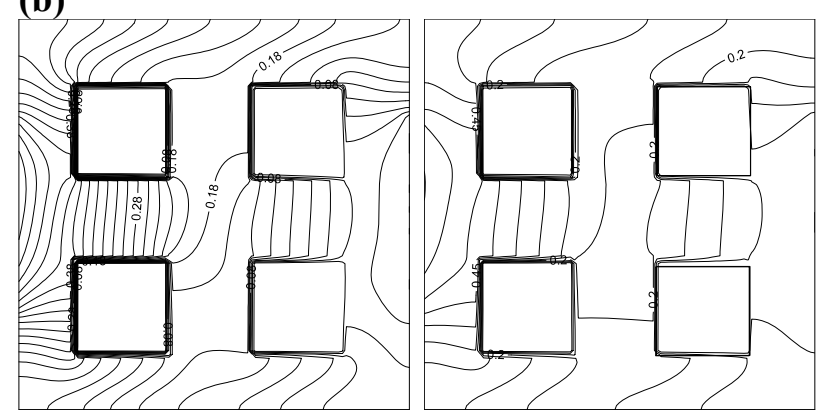

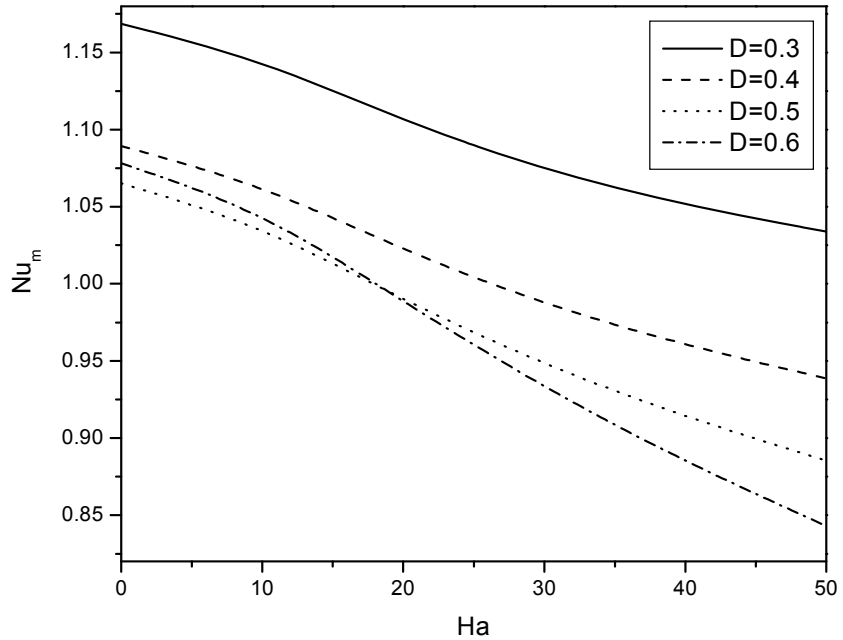

Fig.8b.Variation of the average Nusselt number for $\phi=0.05, B=0.5, Q=1.0, \mathrm{Ri}=10.0$, $\lambda_{t}=-\lambda_{b}=1.0$.
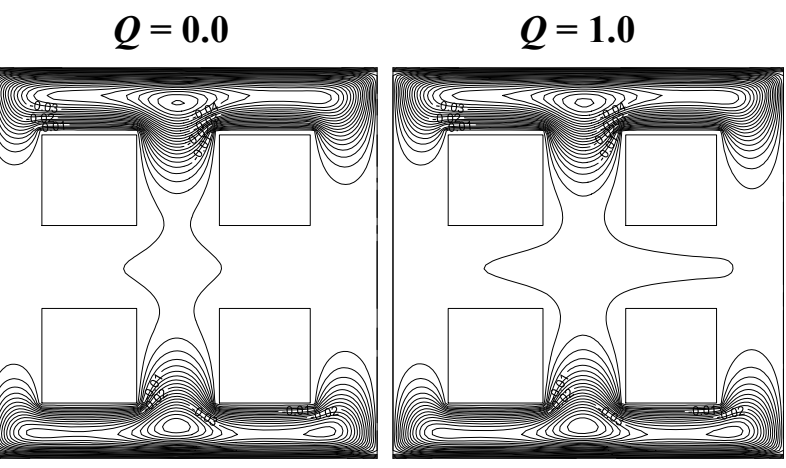

Fig.9a. Streamlines and (b) Isotherms for $D=0.5, B=0.5, \mathrm{Ri}=10.0, \phi=0.05, \mathrm{Ha}=10.0, \lambda_{t}=-\lambda_{b}=1.0$. 


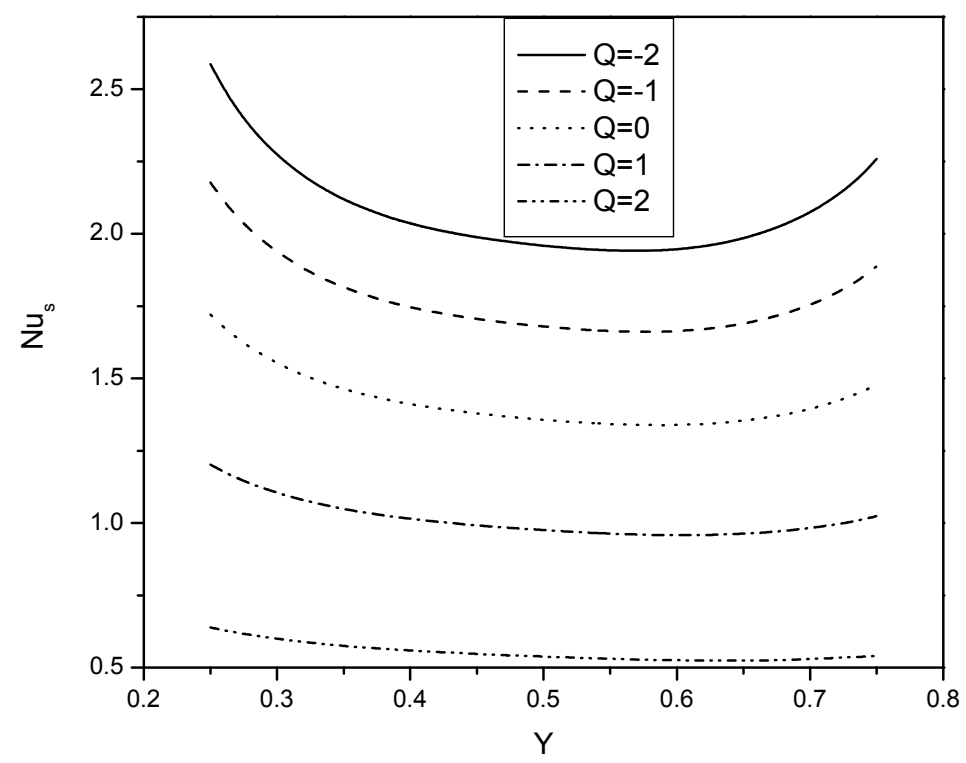

Fig.10. Variation of local Nusselt number along the heat source for $B=0.5, D=0.5, \mathrm{Ri}=10.0$, $\phi=0.05, \mathrm{Ha}=1.0, \lambda_{t}=-\lambda_{b}=1.0$.

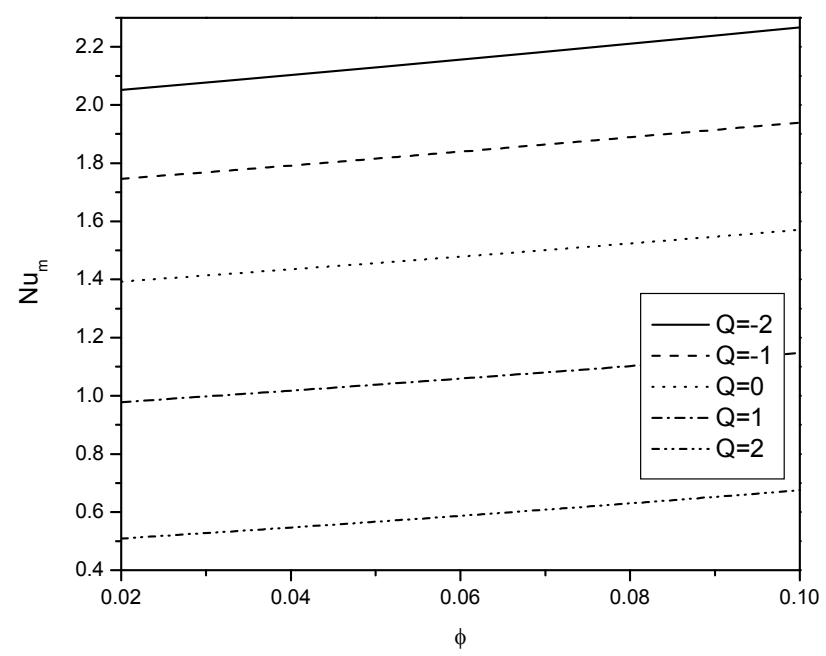

Fig.11a. Variation of the average Nusselt number for $\mathrm{Ha}=10.0, B=0.5, D=0.5, \mathrm{Ri}=10.0$, $\lambda_{t}=-\lambda_{b}=1.0$.

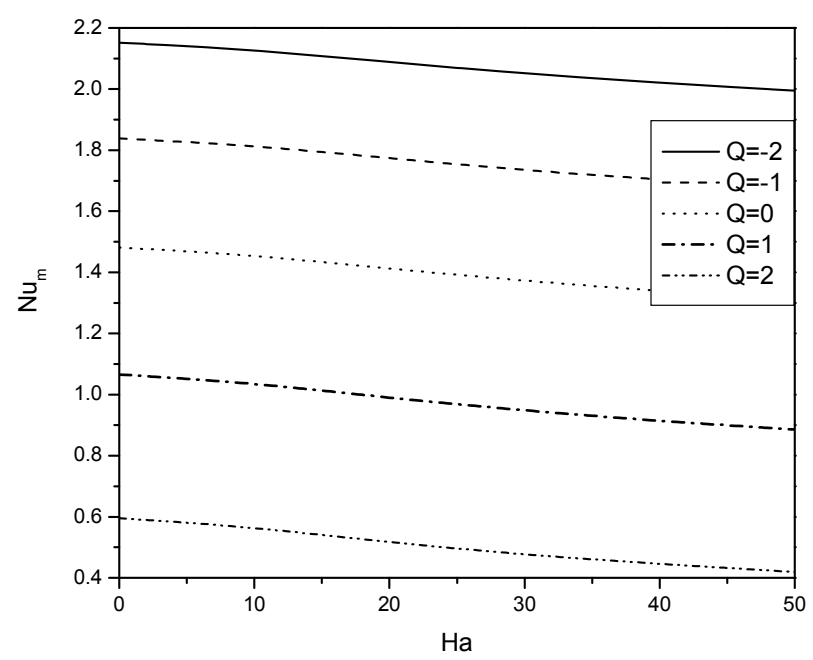

Fig.11b. Variation of the average Nusselt number for $\phi=0.05, D=0.5, B=0.5, \mathrm{Ri}=10.0$, $\lambda_{t}=-\lambda_{b}=1.0$.

Figure 12 shows the influence of the Hartmann number, Ha, on streamlines and isotherm lines for the nanofluid flow in the cavity having obstacles. In streamline plots, the density of the contours increases sufficiently due to an increase in Ha. Therefore, flow strength increases with increasing values of the Hartmann number and the circulation cells tend to elongate between the region in the obstacles. Also, with an increase in Ha, the streamlines are crowded at the top and bottom of the cavity. This is because of the fact that the Lorentz force is less influential as compared to the buoyancy force and the movements of the nanofluid in the enclosure becomes faster than that in the case of $\mathrm{Ha}=0.0$. Similarly, isotherm lines also show a significant impact when Ha increases and the non-linearity of the temperature distribution increases 
with increasing values of Ha. Further, it can be noted that isotherms are concentrated at the adjacent area of the heated block in the mixed convection dominated regions.

(a) $\mathrm{Ha}=0.0$

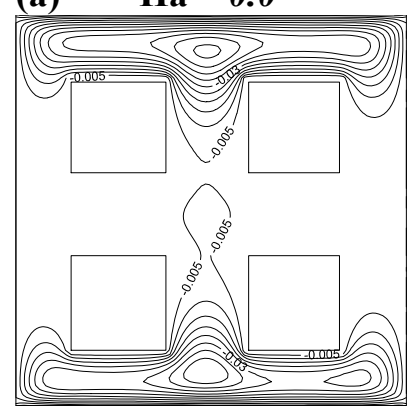

(b)

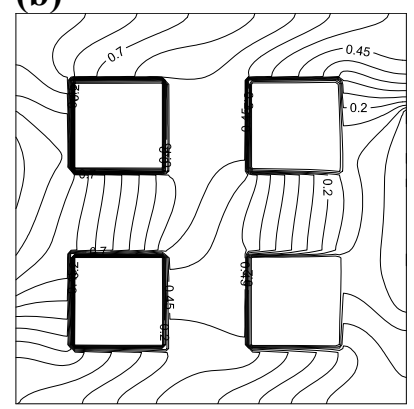

Нa $=10.0$

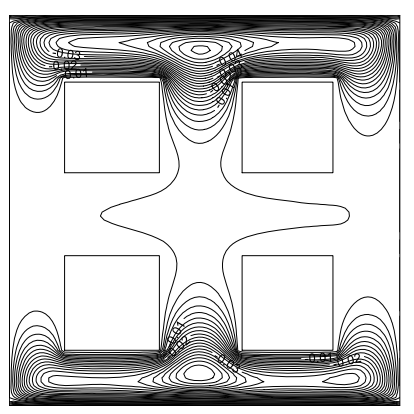

$\mathrm{Ha}=20.0$

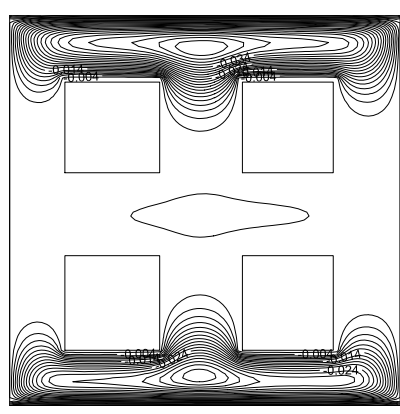

$\mathrm{Ha}=30.0$

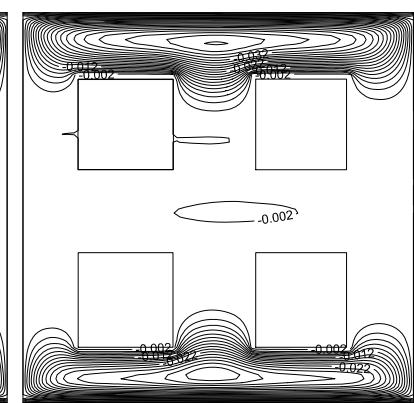

Fig.12. Streamlines and (b) Isotherms for $D=0.5, B=0.5, Q=1.0, \mathrm{Ri}=10.0, \phi=0.05, \lambda_{t}=-\lambda_{b}=1.0$.

Figure 13 describes the effect of Ha on the local and average Nusselt number. It may be noted that both quantities decrease with an increase in the Hartmann number Ha. The heat transfer is dominated by conduction and the additional force (Lorentz force) acting against the flow is responsible for this behavior as it has the tendency to reduce the fluid flow and this force increases as Ha increases.

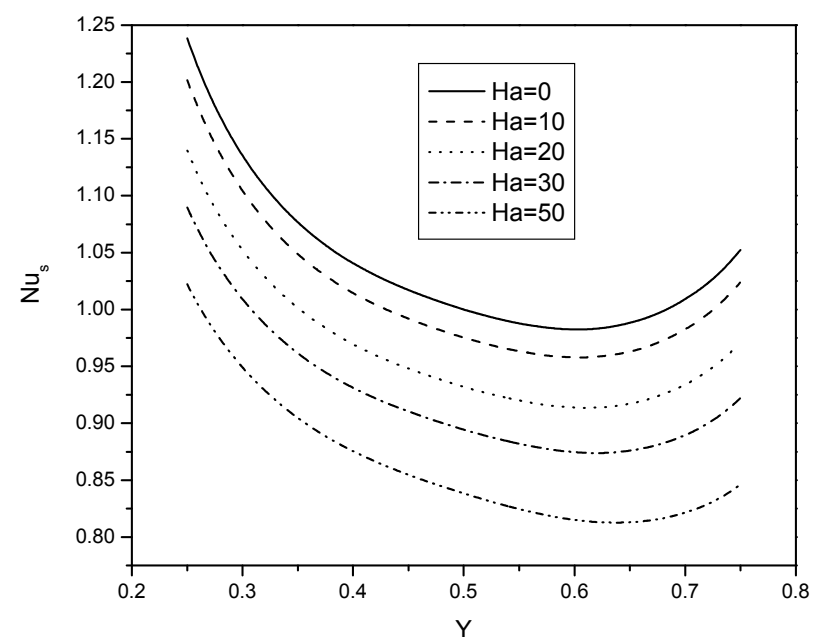

Fig.13a.Variation of local Nusselt number along the heat source for $B=0.5, D=0.5, Q=1.0$, $\mathrm{Ri}=10.0, \phi=0.05, \lambda_{t}=-\lambda_{b}=1.0$.

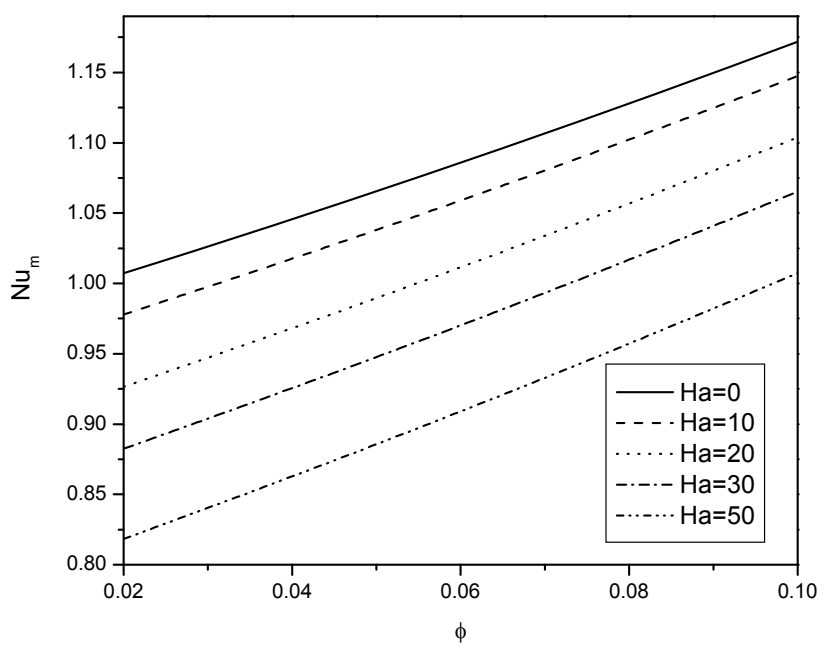

Fig.13b. Variation of the average Nusselt number for $B=0.5, D=0.5, Q=1.0, \mathrm{Ri}=10.0$, $\lambda_{t}=-\lambda_{b}=1.0$. 
(a)
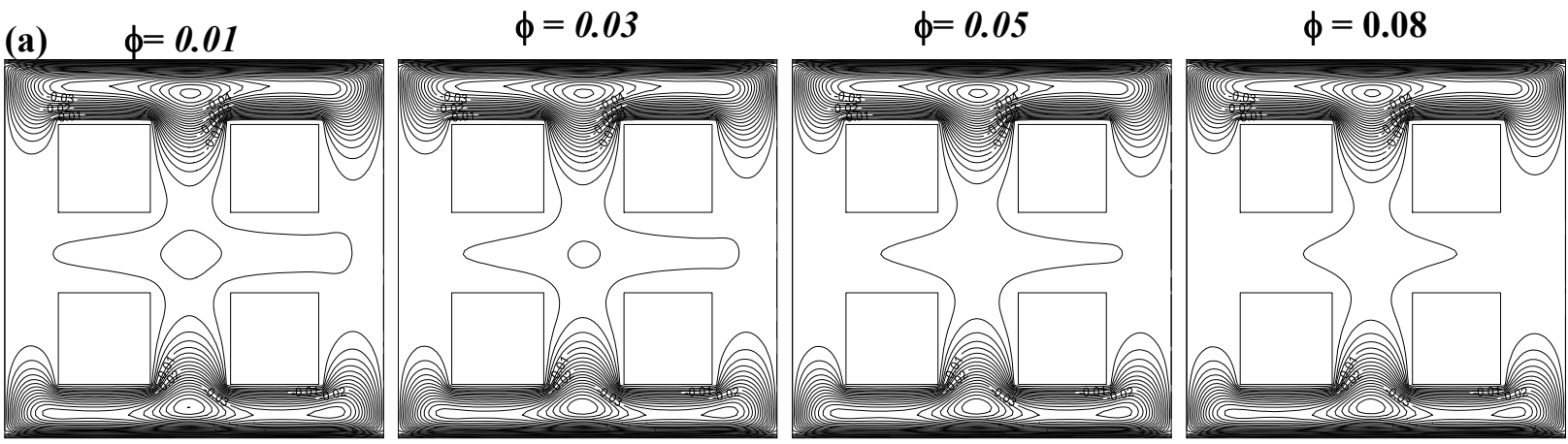

(b)
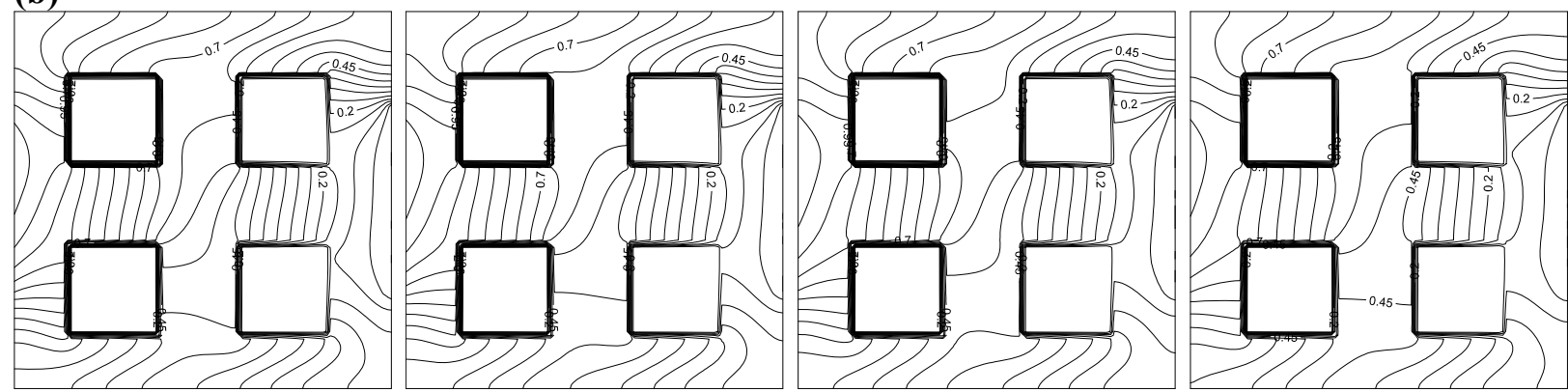

Fig.14a. Streamlines and (b) Isotherms for $D=0.5, B=0.5, Q=1.0, \mathrm{Ri}=10.0, \mathrm{Ha}=10.0, \lambda_{t}=-\lambda_{b}=1.0$.

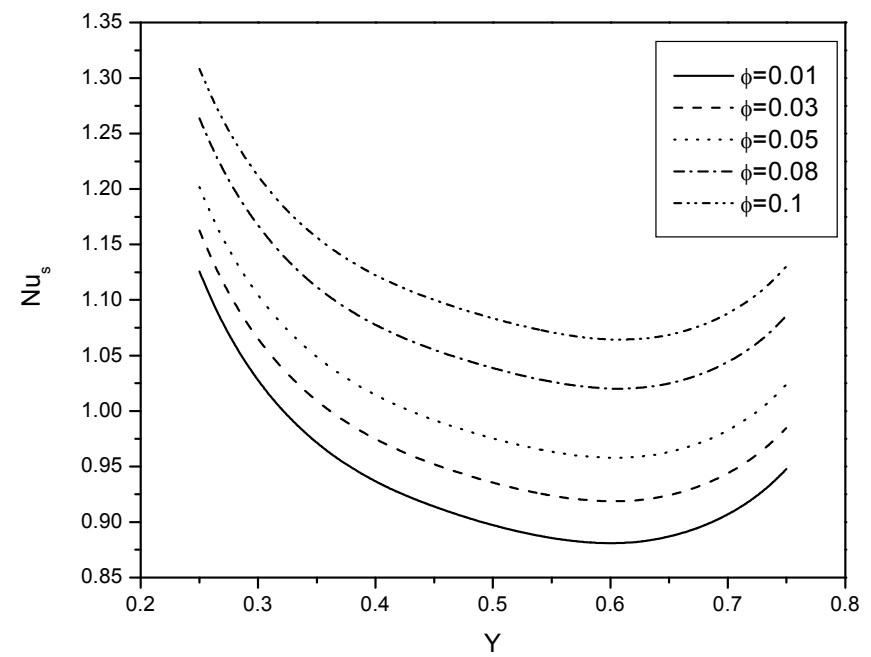

Fig.15a. Variation of local Nusselt number along the heat source for $\mathrm{Ha}=10.0, D=0.5, Q=1.0$, $\mathrm{Ri}=10.0, B=0.5, \lambda_{t}=-\lambda_{b}=1.0$.

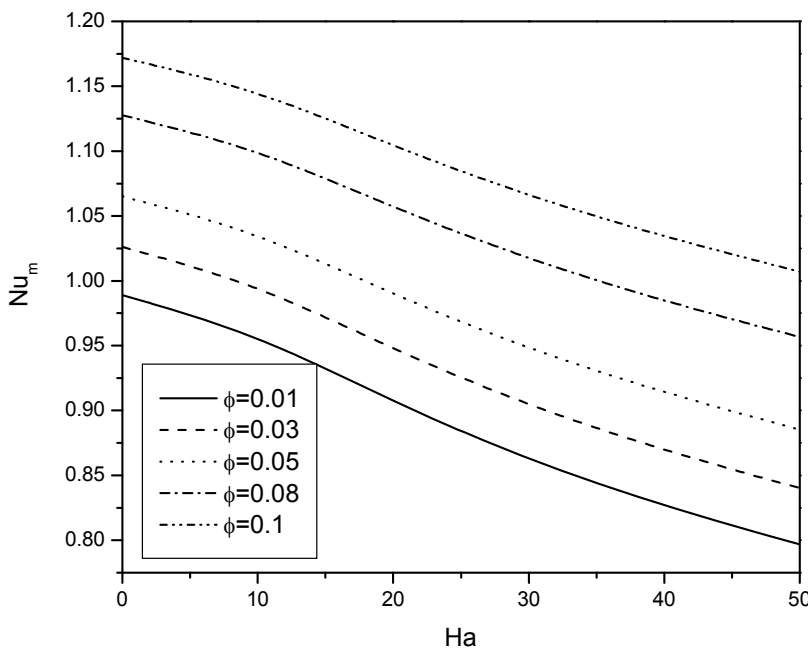

Fig.15b. Variation of the average Nusselt number for $B=0.5, D=0.5, Q=1.0, \mathrm{Ri}=10.0$, $\lambda_{t}=-\lambda_{b}=1.0$.

Figure 14 displays the effect of the nanoparticles volume fraction, $\phi$, on streamlines and isotherm lines for the nanofluid in a cavity. Numerical solution shows that the particle concentration level does not have a significance influence on the shape of the entire streamline cell formed within in the cavity. Usually, rising the solid volume fraction of nanofluid enhances the thermal conductivity and existing temperature and reduces the velocity of the nanofluid but in our case no significant alteration is observed in streamlines and also in isotherms. This may happen due to the position of rigid blocks placed inside the cavity. Solutions are also presented for various values of the nanoparticles volume fraction, $\phi$, on the local Nusselt number and average Nusselt number in Fig.15. One can see that the local and average Nusselt number, i.e., $\mathrm{Nu}_{s}$ and $\mathrm{Nu}_{m}$, diminish when solid particle volume fraction increases from $1 \%$ to $10 \%$. This happens because of the fact that when system increases and the temperature decreases and ultimately the local and average Nusselt number decline. 
The influence of the Richardson number, $\mathrm{Ri}$, is discussed in Fig.16 in terms of streamlines and isotherms. In the case of streamlines, bicellular flow is generated when $R i<10.0$ then certainly the curve for $\mathrm{Ri}=10.0$ develops a connection between these two cells by establishing a cell in the middle of the cavity and finally for a sufficiently high value of $\mathrm{Ri}$ (i.e. for $\mathrm{Ri}=100.0$ ) the usual behaviour is established. Recirculation cells formed for $\mathrm{Ri} \leq 10.0$ are stronger and crowded as compared to those for $R i=100.0$. The streamlines, on the other hand, seem unaltered till $\mathrm{Ri} \leq 10.0$, but for $\mathrm{Ri}=100.0$ the nonlinear distribution of temperature is slightly less dense as compared to that for $\mathrm{Ri} \leq 10.0$. The profiles of the local and average Nusselt number, i.e., $\mathrm{Nu}_{s}$ and $\mathrm{Nu}_{m}$, respectively, are given in Fig.17. This figure shows that both physical quantities increase with increasing Ri because of the increasing effect of buoyancy driven convection.

(a) $\quad \mathrm{Ri}=0.01$

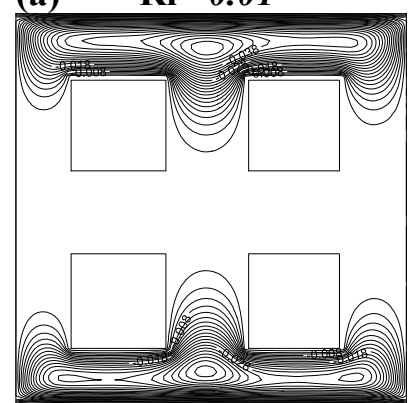

(b)

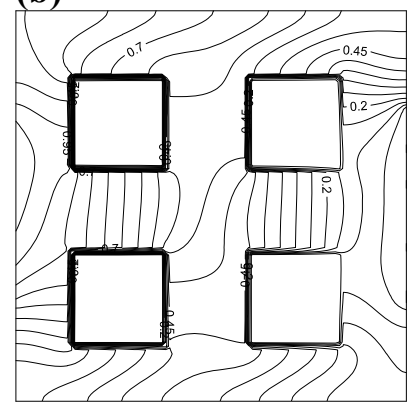

$\mathrm{Ri}=0.1$
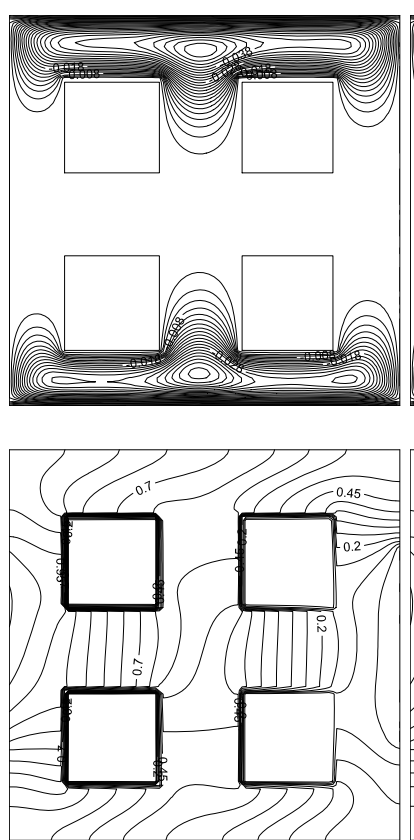

$\mathbf{R i}=1.0$
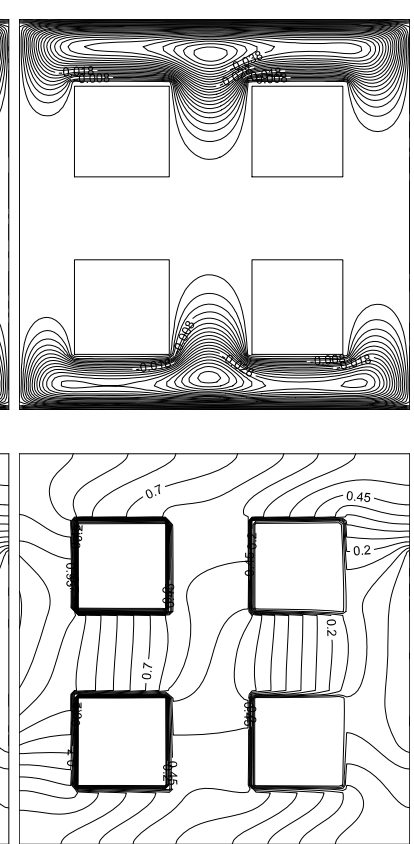

$\mathbf{R i}=10.0$
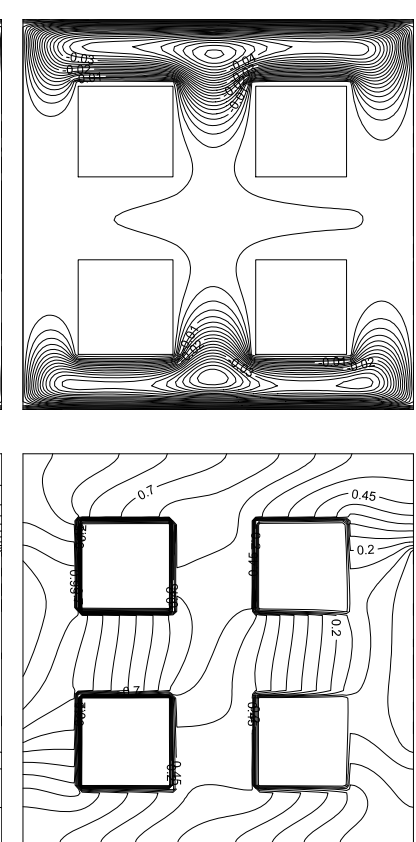

Fig.16a. Streamlines and (b) Isotherms for $D=0.5, B=0.5, Q=1.0, \phi=0.05, \mathrm{Ha}=10.0, \lambda_{t}=-\lambda_{b}=1.0$.

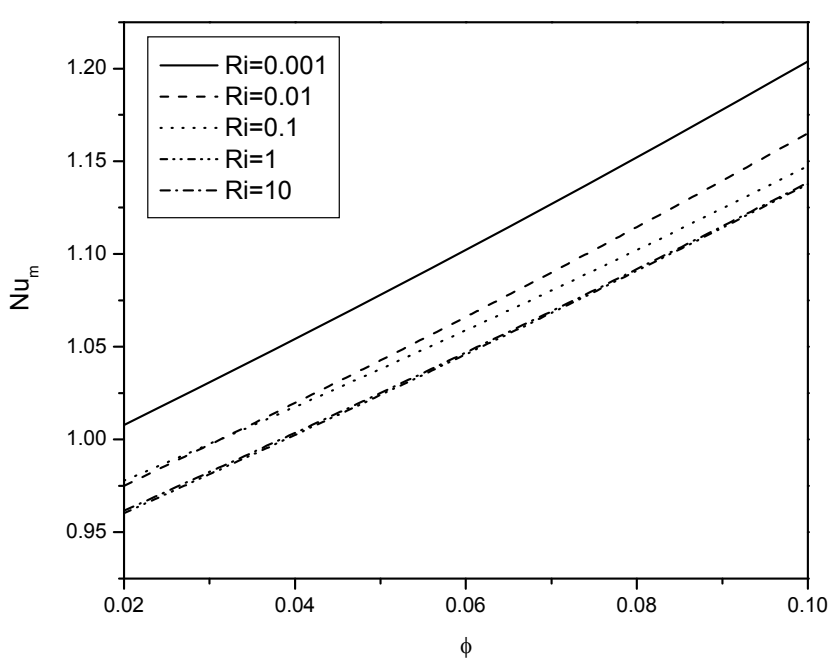

Fig17a.Variation of the average Nusselt number for $\mathrm{Ha}=10.0, D=0.5, Q=1.0, B=0.5$, $\lambda_{t}=-\lambda_{b}=1.0$.

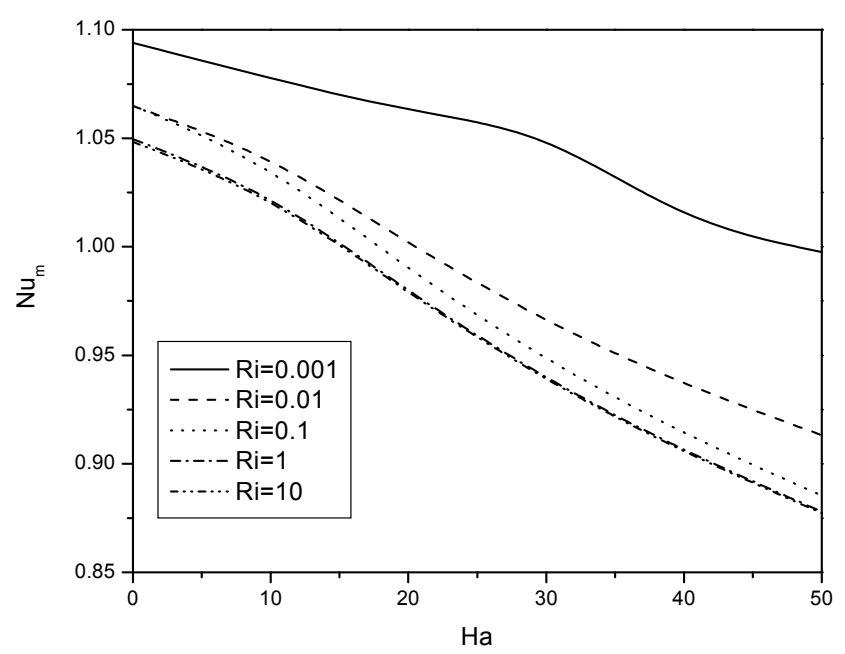

Fig.17b. Variation of the average Nusselt number for $\phi=0.05, D=0.5, Q=1.0, B=0.5$, $\lambda_{t}=-\lambda_{b}=1.0$. 


\section{Conclusion}

In this paper, consideration has been given to the influence of a nanofluid on MHD mixed convection flow in a cavity with internal heat generation. The cavity is loaded with four adiabatic obstacles having discrete heating. The finite volume method is used to obtain the solutions of the problem. For validation of our code and results, comparison is made with the studies available in the literature. The following conclusions are drawn from the present study:

1) Neither an increase in the Richardson number nor increases in the nanoparticle volume fraction affect the isotherm lines inside the cavity, significantly.

2) The local Nusselt number, $\mathrm{Nu}_{s}$, decreases significantly due to an increase in the heat source length parameter, $B$, heat generation parameter, $Q$, Hartmann number, Ha, and nanoparticles volume fraction, $\phi$, when plotted against the heat source.

3) The average Nusselt number, $\mathrm{Nu}_{m}$, decreases due to an increase in the heat source length parameter, $B$, heat generation parameter, $Q$, Hartmann number, Ha, when displayed against the variation of nanoparticles volume fraction, $\phi$.

4) The underlying physical situation has an immense effect on the formation of streamlines when plotted for $Q, \mathrm{Ha}$, Ri.

\section{Nomenclature}

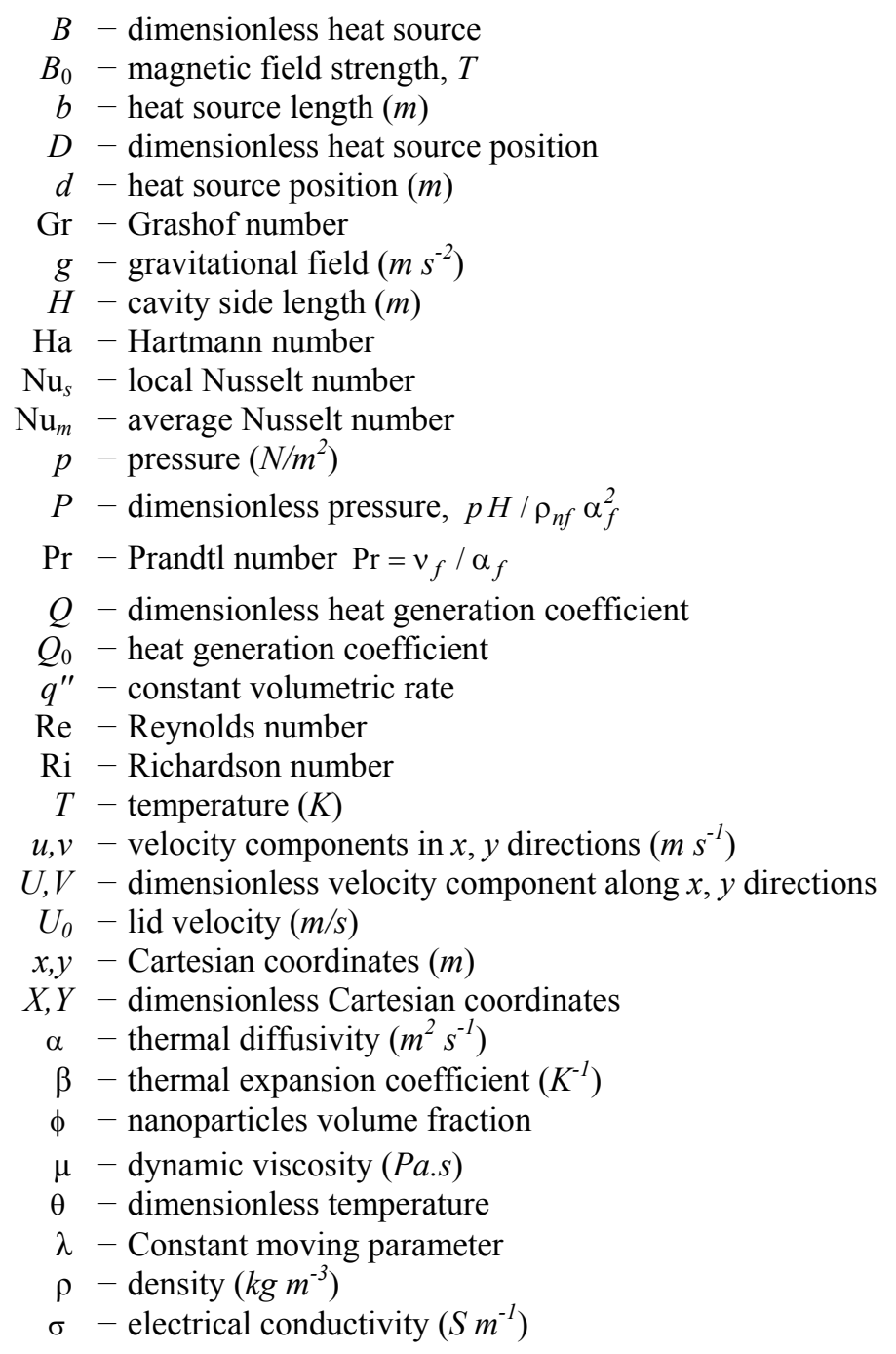




\section{Subscripts}

$$
\begin{aligned}
b & - \text { bottom } \\
C & - \text { cold } \\
C u & - \text { copper } \\
f & - \text { fluid } \\
m & - \text { average } \\
n f & - \text { nanofluid } \\
t & - \text { top }
\end{aligned}
$$

\section{References}

[1] Bagchi A. and Kulacki F.A. (2013): Natural convection in superposed fluid-porous layers.- Springer Briefs in Applied Sciences and Technology, Thermal Engineering and Applied Science, Springer, New York.

[2] Yu W. and Xie H. (2012): A Review on nanofluids: preparation, stability mechanisms, and applications.- J. Nanometer, Article ID 435873, 17 pages doi:10.1155/2012/435873.

[3] Khanafer K. and Vafai K. (2011):A critical synthesis of thermophysical characteristics of nanofluids.- Int. J. Heat Mass Transfer,vol.54,pp.4410-4428.

[4] Choi S.U.S. (1995): Enhancing thermal conductivity of fluids with nanoparticles. - Development and Applications of Non-Newtonian Flows, D.A. Siginer and H.P. Wang, eds., ASME, New York, MD-vol.231 and FED, vol.66, pp.99-105.

[5] Buongiorno J. (2006): Convective transport in nanofluids.- ASME J. Heat Transfer, vol.128, pp.240-250.

[6] Khanafer K., Vafai K. and Lightstone M. (2003): Buoyancy-driven heat transfer enhancement in a twodimensional enclosure utilizing nanofluids.- Int. J. Heat Mass Transfer, vol.46, pp.3639-3653.

[7] Mansour M.A., Mohamed R.A., Abd-Elaziz M.M. and Ahmed S.E. (2010):Numerical simulation of mixed convection flows in a square lid-driven cavity partially heated from below using nanofluid. - Int. Commun. Heat Mass Transfer, vol.37, pp.1504-1512.

[8] Talebi F., Mahmoudi A.H. and Shahi M. (2010): Numerical study of mixed convection flows in a square lid-driven cavity utilizing nanofluid.- Int. Commun. Heat Mass Transfer, vol.37, pp.79-90.

[9] Ghasemi B. and Aminossadati S.M. (2010): Mixed convection in a lid-driven triangular enclosure filled with nanofluids.- Int. Commun. Heat Mass Transfer, vol.37, pp.1142-1148.

[10] Chamkhaa A.J. and Abu-Nada E. (2012): Mixed convection flow in single-and double-lid driven square cavities filled with water-Al2O3 nanofluid: effect of viscosity models. - Eur. J. Mech. B/Fluids, vol.36, pp.82-96.

[11] Abouei Mehrizi A., Farhadi M., Hassanzade Afroozi H., Sedighi K., Rabienataj Darz A.A. (2012): Mixed convection heat transfer in a ventilated cavity with hot obstacle: Effect of nanofluid and outlet port location.- Int. Commun. Heat Mass Transfer, vol.39, pp.1000-1008.

[12] Fatih Selimefendigil and Hakan F. Öztop (2018): Modeling and optimization of MHD mixed convection in a liddriven trapezoidal cavity filled with alumina-water nanofluid: Effects of electrical conductivity models.International Journal of Mechanical Sciences, vol.136, pp.264-278.

[13] Rashad A.M., Muneer A. Ismael, Ali J. Chamkha and Mansour M.A. (2016): MHD mixed convection of localized heat source/sink in a nanofluid-filled lid-driven square cavity with partial slip. - Journal of the Taiwan Institute of Chemical Engineers, vol.68, pp.173-186.

[14] Rashad A.M., Ahmed M., Sameh Khan E., Waqar A. and Mansour M.A. (2017): Inclined MHD mixed convection and partial slip of nanofluid in a porous lid-driven cavity with heat source-sink: effect of uniform and non-uniform bottom heating.- J. Nanofluids, vol.6, pp.368-378.

[15] Muneer A. Ismael, Mansour M.A., Ali J. Chamkha and Rashad A.M. (2016): Mixed convection in a nanofluid filled-cavity with partial slip subjected to constant heat flux and inclined magnetic field.- Journal of Magnetism and Magnetic Materials,vol.15, pp.25-36. 
[16] Kandaswamy P., Sundari S.M. and Nithyadevi N. (2008): Magnetoconvection in an enclosure with partially active vertical walls. - Int. J. Heat Mass Transfer, vol.51, pp.1946-1954.

[17] Nithyadevi N., Kandaswamy P. and Sundari S.M. (2009): Magnetoconvection in a square cavity with partially active vertical walls: time periodic boundary condition. - Int. J. Heat Mass Transfer, vol.52, pp.1945-1953.

[18] Iwatsu R., Hyun J.M. and Kuwahara K. (1993): Mixed convection in a driven cavity with a stable vertical temperature gradient. - Int. J. Heat Mass Transfer, vol.36, pp.1601-8.

[19] Aminossadati S.M. and Ghasemi B. (2009): Natural convection cooling of a localized heat source at the bottom of a nanofluid-filled enclosure. - Eur. J. Mech. B/Fluids, vol.28, pp.630-40.

[20] Khanafer K., Vafai K. and Lightstone M. (2003): Buoyancy-driven heat transfer enhancement in a two dimensional enclosure utilizing nanofluids. - Int. J. Heat Mass Transfer, vol.46, pp.3639-53.

[21] Abu-Nada E. and Chamkha A.J. (2010): Effect of nanofluid variable properties on natural convection in enclosures filled with anCuO-EG-water nanofluid. - Int. J. Therm. Sci.vol.49, pp.2339-52.

[22] Maxwell J.A. (1904): Treatise on electricity and magnetism. - 2nd ed. Cambridge, UK: Oxford University Press.

[23] Brinkman H.C. (1952): The viscosity of concentrated suspensions and solution. - J. Chem. Phys., vol.20, pp.57181.

[24] Patankar S.V. (1980): Numerical Heat Transfer and Fluid Flow. - New York: Hemisphere.

[25] Khanafer K.M. and Chamkha A.J. (1999): Mixed convection flow in a lid-driven enclosure filled with a fluidsaturated porous medium.- Int. J. Heat Mass Transf., vol.31, pp.1354-1370.

[26] Iwatsu R., Hyun J.M. and Kuwahara K. (1993): Mixed convection in a driven cavity with a stable vertical temperature gradient.- Int. J. Heat Mass Transf., vol.36, pp.1601-1608.

Received: July 10, 2018

Revised: February 14, 2020 